\title{
Improvement of nutritional status and incidence of infection in hospitalised, enterally fed elderly by feeding of fermented milk containing probiotic Lactobacillus johnsonii La1 (NCC533)
}

\author{
Yoichi Fukushima $^{1,2}$, Shingo Miyaguchi ${ }^{3}$, Toshihiko Yamano ${ }^{1}$, Tomoko Kaburagi ${ }^{4}$, Hisakazu Iino ${ }^{5}$, \\ Kazunari Ushida ${ }^{6}$ and Kazuto Sato ${ }^{4}$ \\ ${ }^{1}$ Nutrition Business Group, Nestlé Japan Ltd, Tokyo, Japan \\ ${ }^{2}$ Nestlé Research Centre, Nestec Ltd, PO Box 44, Vers-chez-les-Blanc, CH-1000 Lausanne 26, Switzerland \\ ${ }^{3}$ Harunaso Hospital, Gunma, Japan \\ ${ }^{4}$ Department of Food and Nutrition, Japan Women's University, Tokyo, Japan \\ ${ }^{5}$ Department of Food Science and Nutrition, Showa Women's University, Tokyo, Japan \\ ${ }^{6}$ Laboratory of Animal Science, Kyoto Prefectural University, Kyoto, Japan
}

(Received 4 July 2006 - Revised 3 April 2007 - Accepted 10 April 2007)

\begin{abstract}
Probiotics have potential to improve host immunity; however, there is less evidence showing their efficacy against infections and nutritional status in the elderly. We conducted a double-blinded feeding trial in the elderly to elucidate the effect of fermented milk containing Lactobacillus johnsonii $\mathrm{La} 1\left(\mathrm{LC} 1{ }^{\circledR}\right)$ on infections and nutritional status. Twenty-four completely enterally fed elderly in-patients aged over 70 years were randomly assigned into two groups. All subjects were administered $3768 \mathrm{~kJ}(900 \mathrm{kcal}) / \mathrm{d}$ of total enteral nutrition (EN) through tube feeding for 12 weeks. Subjects in the LC1 group were administered $373 \mathrm{~kJ}(89 \mathrm{kcal}) / \mathrm{d}$ of LC1 fermented milk after feeding of $3395 \mathrm{~kJ}(811 \mathrm{kcal}) / \mathrm{d}$ of EN for $12 \mathrm{weeks}$. In the control group, $373 \mathrm{~kJ} / \mathrm{d}$ of the same EN was replaced from the fermented milk. In the LC1 group, the percentage of days with infections during the run-in observation period was 15.4 (SD 17.3) \%, which significantly decreased to 5.7 (SD 8.1) \% during the intervention period $(P=0 \cdot 018)$, and the reduction was larger than that of the control group $(P=0 \cdot 047)$. Blood Hb increased $(P<0 \cdot 05)$, and there was a tendency towards an increase in serum albumin and a decrease in TNF- $\alpha$ (a pro-inflammatory cytokine) in the LC1 group. There was a trend towards an increase in blood phagocytic activity (a natural immunity marker) in the subjects whose initial level was low in the LC1 group. There were no changes in those parameters in the control group. Administration of fermented milk containing the probiotic L. johnsonii La1 may contribute to suppressing infections by improving nutritional and immunological status in the elderly.
\end{abstract}

Human studies: Elderly enterally fed in-patients: Probiotics: Infection: Nutritional status

The proportion of elderly amongst many Western populations is increasing; for example, the proportion of individuals aged over 65 years in Japan is $20 \%$, and is estimated to increase to $26 \%$ in $2015^{1}$. Accordingly, healthcare expenditure is increasing, which becomes a socio-economic issue ${ }^{2}$. Morbidity and mortality by infectious diseases are high in the elderly ${ }^{3}$, where natural defence systems including immune functions are compromised, which give a primary cause of increase in disease risks ${ }^{4,5}$. Nutritional status decreases in the elderly, especially in hospitalised and enterally fed elderly ${ }^{6,7}$, which also causes dysregulation of the immune system ${ }^{8,9}$. Longevity may be associated with genotype of pro- and anti-inflammatory cytokines, TNF- $\alpha$ and IL-10 production ${ }^{10}$, suggesting that inflammation, a component of immunity, may also have an influence on health in the elderly. Several research groups have demonstrated that nutritional supplementation using micronutrients and/or fish oil improves immune function and frequency of infections ${ }^{11-13}$, but the effects are sometimes not or partially observed ${ }^{14,15}$.

The intestinal microbiota play a key role in providing defence systems called colonisation resistance ${ }^{16}$ to keep out invading pathogenic bacteria. Changes in intestinal microbiota balance are reported in the elderly ${ }^{17,18}$, which may attenuate the host defence ${ }^{19}$. Probiotics, defined as live micro-organisms which when administered in adequate amounts confer a health benefit on the host $\mathrm{t}^{20,21}$, are potential measures to regulate infections in the elderly. Some probiotic bacteria have been shown to improve host immunity ${ }^{22}$ and incidence of infections such as infectious diarrhoea in infancy ${ }^{23}$ and respiratory infections in children and adults ${ }^{24,25}$. It has been shown recently that administration of a Lactobacillus strain for 3 weeks reduced the duration of winter infection in free-living elderly $^{26}$. The WHO suggested that probiotics are helpful in normalising nutritional status in children ${ }^{27}$; however, there is

Abbreviations: EN, enteral nutrition; LC1, Lactobacillus johnsonii La1.

* Corresponding author: Dr Yoichi Fukushima, fax +41 21785 8524, email yoichi.fukushima@rdls.nestle.com 
less information of the impact of probiotics on nutritional status in the elderly, especially in combination with other health-status changes including infection, immune status and intestinal microbiota.

Lactobacillus johnsonii La1 (NCC533) is a probiotic strain which is adhesive onto intestinal epithelial cells ${ }^{28}$ and produces bactericidal compounds against harmful bacteria such as Salmonella ${ }^{29}$. Feeding of fermented milk containing L. johnsonii La1 has been demonstrated to reinforce human leucocyte phagocytic activity ${ }^{30}$, antigen-specific IgA antibody production in healthy adults ${ }^{31}$, and improve intestinal microbiota to enrich bifidobacteria in healthy adults ${ }^{32}$. The immune modification by the La1 strain also regulates inflammatory responses, the production of pro-inflammatory cytokines in vitro is suppressed ${ }^{33,34}$ and gastric inflammation is reduced by its intake in Helicobacter pylori-infected human subjects ${ }^{35,36}$. Therefore, the probiotic strain has potential to improve the health status of elderly, whose immunological status may be compromised and who are prone to suffer from infectious diseases.

To reveal the effect of fermented milk containing the probiotic L. johnsonii La1 on the incidence of infection, immunological and nutritional status, and intestinal microbiota in elderly subjects, we conducted a 12 -week feeding trial in a randomised double-blind controlled manner on bed-ridden elderly subjects being fed total enteral nutrition (EN) in hospital, whose food intake was nutritionally standardised.

\section{Materials and methods}

\section{Subjects}

The trial was conducted in accordance with the Helsinki declaration (2000) and the protocol was approved by the Ethical Committee of Harunaso Hospital (Gunma, Japan). Elderly volunteers were enrolled from bed-ridden in-patients over 70 years of age at Harunaso Hospital suffering from dysphasia with dementia and fed total EN by nasogastric tube or gastrostomy. After obtaining the agreement of the volunteers and their family members on the objectives and the design of the study, seven men and seventeen women (age 75-96 years) were enrolled.

\section{Study design and diet}

The study was conducted during the winter season of 2002-3. Subjects were randomly assigned to two groups, the L. johnsonii La1 (LC1) and control groups, and a double-blind controlled study was conducted. The profile of the subjects is shown in Table 1. Test fermented milk $\left(\mathrm{LC} 1^{\circledR}\right.$; Nestlé Japan Ltd, Tokyo, Japan) contained the probiotic strain L. johnsonii La1 (NCC533) at $10^{9}$ colony-forming units and a non-probiotic strain Streptococcus thermophilus at $10^{8}$ colony-forming units $/ 90 \mathrm{~g}$. In the run-in observation period for the first 12 weeks, all subjects were administered total EN at $3768 \mathrm{~kJ}$ (900 kcal)/d (CZ-Hi; Clinico Co., Ltd, Tokyo, Japan). In the intervention period for the subsequent 12 weeks, subjects in the LC1 group ( $n$ 12) were administered $90 \mathrm{~g}(373 \mathrm{~kJ}$ $(89 \mathrm{kcal})$ ) fermented milk through a tube after feeding of EN at $3395 \mathrm{~kJ}(811 \mathrm{kcal}) / \mathrm{d}$. The fermented milk was served in a liquid form by mixing it with water in a kitchen, as we did for the control EN preparation, in order to maintain blind conditions. The subjects in the control group were administered the EN diet at $3395 \mathrm{~kJ}(811 \mathrm{kcal}) / \mathrm{d}$, then administered $373 \mathrm{~kJ}$ $(89 \mathrm{kcal})$ of the EN in the same manner as the fermented milk in the LC1 group. The diets in the two groups were nutritionally comparable (Table 2).

All subjects were under nursing care during the entire study period. Health-status parameters including body temperature, faecal condition (the shape of faeces and stool extraction or usage of laxatives for defaecation) and usage of drugs were recorded on a daily basis. Blood and faecal samples were collected before and during the intervention period to assess nutritional and immune status. The number of days of infection was counted when the subjects were diagnosed by a physician as suffering from infections requiring prescribed antibiotics. Infection, for which antibiotics are prescribed, is frequently observed in the elderly, and we did not exclude such subjects in our study design and continued the observation and sampling. A physician comprehensively diagnosed respiratory, intestinal or urinary tract infection taking into account respiratory inflammation, appearance of sputum, coughing and sneezing, turbidity of urine, watery defaecation and fever. Duration of infections was expressed in percentage of days with infections for 12 weeks.

\section{Blood and faecal analysis}

Blood samples were collected from the femoral artery at three time points: just before starting the intervention period (week 0), and at 4 and 12 weeks during that period. Serum total protein, albumin, total cholesterol, creatinine, aspartate aminotransferase, alanine aminotransferase, blood urea nitrogen, C-reactive protein, IgG and $\operatorname{IgA}$ were measured using a Hitachi 7600 autoanalyser (Hitachi, Tokyo, Japan), and blood cell numbers were measured with an SE-9000 autoanalyser (Sysmex, Kobe, Japan). Cholinesterase activity was measured using the butyrylthiocholine-5,5'-dithiobis-2-nitrobenzoic acid colorimetric assay. TNF- $\alpha$ was measured using an ELISA kit (Japan Immunoresearch Lab, Takasaki, Japan), and phagocytic activity were measured with a PHAGOTEST kit (Orpegen Pharma, Heidelberg, Germany) using fluorescein

Table 1. Characteristics of subjects

\begin{tabular}{lcc}
\hline & LC1 group & Control group \\
\hline Subjects $(n)$ & 12 & 12 \\
Males $(n)$ & 4 & 3 \\
Females $(n)$ & 8 & 9 \\
Serum albumin $<35 \mathrm{~g} / \mathrm{l}(n)$ & 6 & 7 \\
Age (years) & & \\
Mean & 84.4 & $84 \cdot 8$ \\
SD & $6 \cdot 2$ & $7 \cdot 0$ \\
Age range (years) & $75-95$ & $75-96$ \\
Body weight (kg) & $39 \cdot 0$ & $36 \cdot 7$ \\
Mean & $2 \cdot 9$ & 3.9 \\
SD & & \\
Major episodes & 8 & 11 \\
Cerebrovascular diseases & 1 & 0 \\
Cardiovascular diseases & 2 & 0 \\
Diabetes & 1 & 1 \\
Respiratory diseases & & \\
\hline
\end{tabular}

LC1, Lactobacillus johnsonii La1. 
Table 2. Daily intake of energy and nutrients

\begin{tabular}{|c|c|c|c|}
\hline & \multirow{2}{*}{$\begin{array}{l}\text { Observation period } \\
\text { All subjects }\end{array}$} & \multicolumn{2}{|c|}{ Intervention period } \\
\hline & & LC1 group $(E N+L C 1)$ & Control group (EN) \\
\hline Total energy $(\mathrm{kJ} / \mathrm{d})$ & 3768 & 3768 & 3768 \\
\hline Total energy $(\mathrm{kcal} / \mathrm{d})$ & 900 & 900 & 900 \\
\hline $\mathrm{Cz}-\mathrm{Hi}$ (Clinico Co. Ltd) (kJ/d) & 3768 & 3395 & 3768 \\
\hline $\mathrm{Cz}-\mathrm{Hi}(\mathrm{kcal} / \mathrm{d})$ & 900 & 811 & 900 \\
\hline LC1 yogurt (Nestlé Japan Ltd)* $(\mathrm{kJ} / \mathrm{d})$ & 0 & 373 & 0 \\
\hline LC1 yogurt* $(\mathrm{kcal} / \mathrm{d})$ & 0 & 89 & 0 \\
\hline Protein $(\mathrm{g} / \mathrm{d})$ & 45 & 45 & 45 \\
\hline Lipid $(\mathrm{g} / \mathrm{d})$ & 20 & 20 & 20 \\
\hline Carbohydrates $(\mathrm{g} / \mathrm{d})$ & 136 & 136 & 135 \\
\hline Dietary fibre $(\mathrm{g} / \mathrm{d})$ & 18 & 16 & 18 \\
\hline $\mathrm{Zn}(\mathrm{mg} / \mathrm{d})$ & 10 & 9 & 10 \\
\hline Oligosaccharides $(\mathrm{g} / \mathrm{d})$ & 0.5 & 0.4 & 0.5 \\
\hline$D H A+E P A(g / d)$ & 0.5 & 0.4 & 0.5 \\
\hline
\end{tabular}

isothiocyanate-labelled Escherichia coli and a flow cytometric technique. Phagocytic activity and TNF- $\alpha$ were measured only at 0 and 4 weeks in order to diminish the burden for the subjects.

Faecal microbiota were analysed according to the method of Mitsuoka et al. $^{37}$ with slight modification ${ }^{38}$. Faecal total bacteria, total anaerobes, total aerobes, Bacteroidaceae, Bifidobacterium, Clostridium, Enterobacteriaceae, Enterococcus and Lactobacillus were counted using CDC anaerobe blood, BBE, lactobacilli-selective, and CCFA agar media (Nippon Becton Dickinson Co., Ltd, Tokyo, Japan), KM-CW egg yolk, DHL, and EF agar media (Nissui Pharmaceutical Co., Ltd, Tokyo, Japan), blood liver and bifidobacteria-selective agar, and sheep blood agar M58 media (Eiken Chemical Co., Ltd, Tokyo, Japan), and CPS IPD agar medium (Biomerieux Japan, Tokyo, Japan). Faecal methicillin-resistant Staphylococcus aureus were also counted using mannitol salt agar medium (Nissui Pharmaceutical Co., Ltd), and OPA Staphyrococcus agar medium (Nippon Becton Dickinson Co., Ltd). Faecal samples were stored anaerobically using Anaero Pack Kenki (Mitsubishi Gas Chemical, Tokyo, Japan) at $4^{\circ} \mathrm{C}$ and analysed within $24 \mathrm{~h}$ after defaecation. Decimal dilution series of faecal samples into anaerobic PBS were prepared and samples were plated on to selective and non-selective media and incubated under anaerobic or aerobic conditions. Bacterial species were identified by colony morphology, gram staining, cell morphology, aerobic growth and biochemical test for sporulation. The three and two subjects in the LC1 and control groups, respectively, who took antibiotics in the $7 \mathrm{~d}$ before faecal sampling were excluded from faecal analysis, because the microbiota are known to be significantly disturbed by antibiotics ${ }^{39}$.

\section{Statistical analysis}

The results are expressed as mean values and standard deviations. Data were analysed with SPSS $11.0 \mathrm{~J}$ software (SPSS Japan, Tokyo, Japan). Statistical differences between the LC1 and control groups, and between before and during intervention periods were examined using the Wilcoxon rank sum test. Statistical difference on the appearance ratio of faecal bacteria was examined with the $\chi^{2}$ test. The difference between means was considered significant at $P<0 \cdot 05$.

\section{Results}

\section{Clinical observations}

All subjects accepted the diet well with or without fermented milk containing $L$. johnsonii La1 and no adverse health conditions were observed during the entire study period. No subjects received any vaccination in the study periods. Table 3 and Fig. 1 show the duration of infections and the health status of the subjects. There was no difference in duration of infections, diarrhoea or fever during the observation period between the LC1 and control groups. In the LC1 group, the duration of infections (percentage of days) in the observation period was $15.4(\mathrm{SD} 17 \cdot 3) \%$ which significantly lowered to $5 \cdot 7$ (SD 8.1) $\%$ in the intervention period $(P=0.018)$, and the reduction was larger in the $\mathrm{LC} 1$ group than that in the control group $(P=0 \cdot 047)$. Respiratory symptoms were most frequently found, and they improved in the LC1 group, but incidence of the others without respiratory symptoms was low and such improvement was undetectable. Decrease in the duration of fever at $>37^{\circ} \mathrm{C}$ tended to be larger in the $\mathrm{LC} 1$ group than that in the control group $(P=0.078)$. In the control group, there were no differences in the duration of infection or fever between the two periods. There were no changes in defaecation conditions including usage of laxatives and watery faecal excretion not caused by laxatives in both groups during the entire study period (Table 3 ).

\section{Nutritional and immunological status}

The changes in nutritional status and the other blood biomarkers are shown in Table 4 . Hb concentration in blood increased in the LC1 group, and was significantly higher than that of the control group at 4 weeks $(P=0 \cdot 038)$. There were no statistical differences between the LC1 group and the control group for other blood biomarkers, but changes were observed within the LC1 group; that is; serum albumin at 12 weeks during the intervention period was higher $(P=0.034)$ than that before intake (week 0$)$, cholinesterase increased at 4 weeks $(P=0.028)$ and remained at a similar level at week 12 , and total protein tended to increase from 0 to 12 weeks $(P=0 \cdot 052)$. Erythrocyte and leucocyte numbers increased at 4 weeks and 12 weeks in the LC1 group, 
Table 3. Infection, body temperature and faecal conditions in elderly subjects

(Mean values and standard deviations)

\begin{tabular}{|c|c|c|c|c|c|c|c|c|c|c|c|c|}
\hline & \multicolumn{6}{|c|}{ LC1 group ( $n$ 12) } & \multicolumn{6}{|c|}{ Control group ( $n$ 12) } \\
\hline & \multicolumn{2}{|c|}{$\begin{array}{l}\text { Observation period } \\
(-11 \text { to } 0 \text { weeks }) \ddagger\end{array}$} & \multicolumn{2}{|c|}{$\begin{array}{l}\text { Intervention period } \\
\text { (1 to } 12 \text { weeks) }\end{array}$} & \multicolumn{2}{|c|}{ Difference } & \multicolumn{2}{|c|}{$\begin{array}{l}\text { Observation period } \\
(-11 \text { to } 0 \text { weeks }) \ddagger\end{array}$} & \multicolumn{2}{|c|}{$\begin{array}{l}\text { Intervention period } \\
\text { (1 to } 12 \text { weeks) }\end{array}$} & \multicolumn{2}{|c|}{ Difference } \\
\hline & Mean & SD & Mean & SD & Mean & SD & Mean & SD & Mean & SD & Mean & SD \\
\hline Body temperature $\left({ }^{\circ} \mathrm{C}\right)$ & $36 \cdot 75$ & 0.39 & $36 \cdot 76$ & 0.42 & 0.02 & 0.16 & $36 \cdot 83$ & 0.36 & $36 \cdot 89$ & 0.35 & 0.06 & 0.35 \\
\hline \multicolumn{13}{|l|}{ Duration of fever ( $\%$ of days in 12 weeks) } \\
\hline$>37.0^{\circ} \mathrm{C}$ & 27.4 & $19 \cdot 0$ & 23.4 & 14.5 & -4.0 & $15 \cdot 0$ & $29 \cdot 1$ & $22 \cdot 8$ & 37.1 & $23 \cdot 3$ & 8.1 & $18 \cdot 7$ \\
\hline$>37.5^{\circ} \mathrm{C}$ & 4.7 & $6 \cdot 1$ & 3.9 & $3 \cdot 2$ & -0.8 & 4.4 & 4.9 & $7 \cdot 0$ & $7 \cdot 1$ & $8 \cdot 1$ & $2 \cdot 2$ & 5.9 \\
\hline$>38.0^{\circ} \mathrm{C}$ & 1.9 & 2.7 & 1.6 & 1.7 & -0.4 & 1.7 & 0.1 & 0.3 & 1.1 & $2 \cdot 8$ & 1.0 & 2.9 \\
\hline Duration of infection (\% of days in 12 weeks) & $15 \cdot 4$ & $17 \cdot 3$ & $5 \cdot 7^{*}$ & 8.1 & $-9.6 \dagger$ & $10 \cdot 9$ & $13 \cdot 7$ & 21.5 & $10 \cdot 7$ & $14 \cdot 7$ & -3.0 & 14.7 \\
\hline \multicolumn{13}{|l|}{ Defaecation ( $\%$ of days in 12 weeks) } \\
\hline Normal & $27 \cdot 4$ & 21.4 & $23 \cdot 1$ & $20 \cdot 8$ & $-4 \cdot 3$ & $20 \cdot 9$ & $23 \cdot 7$ & $19 \cdot 6$ & $26 \cdot 6$ & $25 \cdot 0$ & $2 \cdot 9$ & $16 \cdot 6$ \\
\hline Extraction & 3.7 & 4.7 & 5.5 & $5 \cdot 1$ & 1.9 & $2 \cdot 6$ & 0.9 & 1.5 & $2 \cdot 1$ & $2 \cdot 3$ & 1.2 & 1.9 \\
\hline Laxative & $21 \cdot 1$ & $13 \cdot 6$ & $24 \cdot 3$ & $22 \cdot 7$ & 3.2 & $14 \cdot 3$ & $29 \cdot 7$ & 24.4 & $25 \cdot 7$ & $26 \cdot 9$ & -3.9 & $19 \cdot 1$ \\
\hline Watery & $2 \cdot 2$ & 3.1 & 1.6 & $2 \cdot 9$ & -0.6 & 4.5 & 0.9 & 2.5 & 4.9 & $11 \cdot 6$ & 4.0 & 9.4 \\
\hline Total & 54.5 & $16 \cdot 9$ & $54 \cdot 6$ & 20.5 & $0 \cdot 1$ & $17 \cdot 5$ & $55 \cdot 2$ & $13 \cdot 1$ & $59 \cdot 3$ & 18.4 & 4.2 & $18 \cdot 7$ \\
\hline
\end{tabular}

LC1, Lactobacillus johnsonii La1.

* Mean value was significantly different from that of the same group before administration $(P<0.05)$.

† Mean difference was significantly different from that of the control group $(P<0.05)$.

$\ddagger$ The run-in observation period was 12 weeks before starting the intervention period for 12 weeks. 
(a)

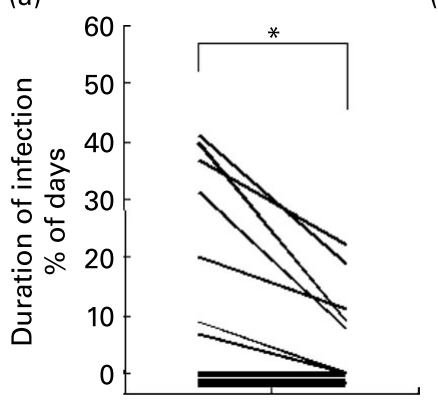

b) 60

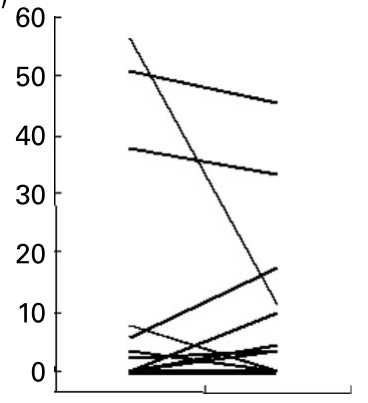

(c)

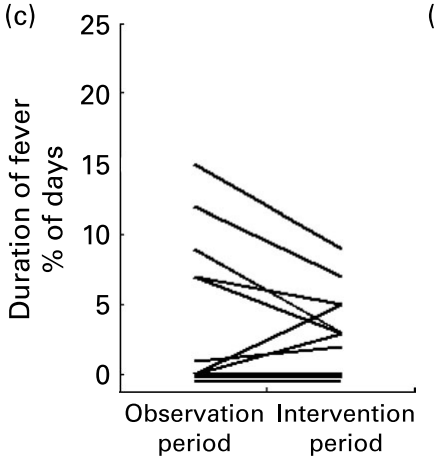

(d) 25

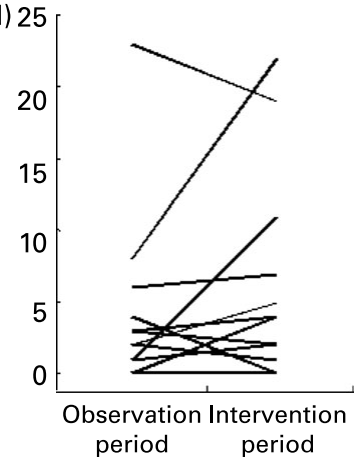

Fig. 1. Durations of infections ( $a$ and $b$ ) and fever of more than $37.5{ }^{\circ} \mathrm{C}$ (c and d) in elderly subjects fed Lactobacillus johnsonii La1 (LC1; $n$ 12; a and c) and in control subjects ( $n 12 ; \mathrm{b}$ and d). Values are means. * Duration of infections (\% of days) during the intervention period was lower than that of the observation period in the LC1 group $(P<0.05)$.

respectively $(P<0 \cdot 05)$. However, this was not significant between groups. The ratio of blood cell types remained unchanged. In the control group, we observed a slight increase in serum albumin, white blood cells and $\mathrm{IgG}$, but the changes were not statistically significant, and the other biomarkers showed no changes. Serum albumin was positively correlated with cholinesterase and total cholesterol at each time point ( $R 0.49-0.67 ; P<0.01)$, but not with total protein. Total cholesterol was slightly increased in the LC1 group, but it was not significant.

There were no significant changes in blood immune biomarkers between groups, but the following trends were evident, before and after treatment in the LC1 group. Blood phagocytic activity was normal at not less than $90 \%$ in twelve out of twenty-four subjects ${ }^{40}$. In the LC1 group, there were six subjects whose initial values were lower than $90 \%$, and they significantly increased from 0 to 4 weeks $(P=0.046 ;$ Table 4). The phagocytic activity in subjects with initially high values showed no changes. Neutrophils, the major blood cells providing phagocytic activity, remained unchanged. Serum TNF- $\alpha$ decreased from 0 to 4 weeks in the LC1 group $(P=0.008)$. Such changes were not observed in the control group (Table 4). There were no differences in serum immune parameters including total $\operatorname{IgG}, \operatorname{IgA}$, and $\mathrm{C}$-reactive protein between the groups.

\section{Faecal microbiota}

The number and proportion of faecal bacteria are shown in Table 5. Total number of faecal bacteria in the elderly subjects

was approximately $10^{10}$ colony-forming units/g wet faeces, which was about ten times lower than that usually found in healthy adults ${ }^{37}$. Bifidobacteria were not found in five out of nineteen subjects (26\%). For both groups, we observed no significant changes in faecal microbiota at any time point. Lactobacillus slightly increased in the LC1 group, but this was not significant. Appearance of methicillin-resistant Staphylococcus aureus decreased from 0 to 12 weeks in the LC1 group ( $P=0 \cdot 016)$, according to reduction of antibiotic usage.

\section{Discussion}

The present study showed that the duration of infections in hospitalised, enterally fed elderly subjects was reduced by the administration of fermented milk containing $L$. johnsonii La1 for 12 weeks. Not only nutrition but also exercise and positive emotion are known to influence the immune system $^{41,42}$. In the present study, all subjects were bedridden in-patients treated with total $\mathrm{EN}$, and suffering from dementia. Their life circumstances were quite similar, nutritionally, mentally and physically. Although the number of subjects in the study was limited, the homogeneous living conditions and health status of the subjects allowed us to demonstrate that feeding of fermented milk containing the La1 strain is a potential way to decrease infections. In the present study, we used the test fermented milk containing not only the probiotic strain $L$. johnsonii La1, but also the non-probiotic strain $S$. thermophilus, and their fermentated metabolites, which makes it difficult to conclude whether the anti-infectious effect was provided solely by the probiotic strain. Dunnet-Huges et al. showed that the elevation of blood phagocytic activity in human subjects fed fermented milk containing $S$. thermophilus is weaker than that containing the La1 strain $^{43}$. Cruchet et al. reported that the anti-H. pylori effect of probiotic feeding with the Lal strain found in children disappeared when the strain was killed by heat treatment ${ }^{36}$. These findings suggest that the live probiotic strain may efficiently exert some health benefits. It is difficult to distinguish the efficacy of the La1 strain from the other elements in the test fermented milk; however, the Lal strain, whose efficacy is well proven, may more largely contribute or efficiently trigger the effects we found in the present study. Some researchers have shown that nutritional supplementation could work to enhance immunity and suppress infectious diseases ${ }^{1-13}$, but they did not always work sufficiently ${ }^{14,15}$ or needed long-term consumption $^{44,45}$. The EN formula we used for both the test and control groups in the present study was already rich in $\mathrm{Zn}$, vitamins and PUFA, suggesting that probiotic feeding may work on top of such nutritional supplements for the elderly.

An interesting finding shown in the present study was that probiotic feeding improved nutritional status, as shown by the increase in serum albumin. We separately conducted a human trial on healthy elderly living at a nursing home with usual meal services, and observed that the administration of fermented milk containing the Lal strain elevated serum albu$\min ^{46}$, implying that the use of fermented milk containing the La1 strain to improve nutritional status could be widely adopted by the elderly not only with tube feeding but also with slight malnutrition that frequently occurs in this age group ${ }^{47}$. Serum cholinesterase, a marker of liver function, was also increased by probiotic feeding. These improvements 
Table 4. Blood biomarkers related health, nutritional, and immunological status

(Mean values and standard deviations)

\begin{tabular}{|c|c|c|c|c|c|c|c|c|c|c|c|c|c|}
\hline & \multirow[b]{3}{*}{ Standard value } & \multicolumn{6}{|c|}{ LCl group ( $n$ 12) } & \multicolumn{6}{|c|}{ Control group ( $n$ 12) } \\
\hline & & \multicolumn{2}{|c|}{0 weeks } & \multicolumn{2}{|c|}{4 weeks } & \multicolumn{2}{|c|}{12 weeks } & \multicolumn{2}{|c|}{0 weeks } & \multicolumn{2}{|c|}{4 weeks } & \multicolumn{2}{|c|}{12 weeks } \\
\hline & & Mean & SD & Mean & SD & Mean & SD & Mean & SD & Mean & SD & Mean & SD \\
\hline \multicolumn{14}{|l|}{ Nutrition status markers } \\
\hline Total protein $(\mathrm{g} / \mathrm{l})$ & $65-82$ & $66 \cdot 7$ & 5.5 & $68 \cdot 0$ & $4 \cdot 8$ & $69 \cdot 1$ & 4.9 & $66 \cdot 2$ & 4.3 & $66 \cdot 7$ & $6 \cdot 1$ & $68 \cdot 3$ & 4.0 \\
\hline Albumin $(\mathrm{g} / \mathrm{l})$ & $35-55$ & 34.3 & $3 \cdot 2$ & $35 \cdot 2$ & $2 \cdot 3$ & $35 \cdot 8^{*}$ & 2.5 & 33.9 & 3.6 & 33.8 & 3.0 & $35 \cdot 0$ & $3 \cdot 2$ \\
\hline Total cholesterol $(\mathrm{mg} / \mathrm{l})$ & $1.300-2.500$ & 1.730 & 0.370 & 1.780 & 0.430 & 1.870 & 0.450 & 1.700 & 0.290 & 1.630 & 0.350 & 1.720 & 0.350 \\
\hline \multicolumn{14}{|l|}{ Immunological status markers } \\
\hline $\lg G(g / l)$ & - & $15 \cdot 930$ & $5 \cdot 290$ & $16 \cdot 600$ & $5 \cdot 740$ & $16 \cdot 450$ & $5 \cdot 620$ & $16 \cdot 160$ & 3.700 & 17.460 & $5 \cdot 100$ & $17 \cdot 600$ & 4.300 \\
\hline $\lg A(g / l)$ & - & 3.430 & 1.650 & 3.510 & 1.690 & 3.370 & 1.710 & 4.010 & 1.980 & $4 \cdot 120$ & 1.920 & 4.170 & 1.950 \\
\hline \multicolumn{14}{|l|}{ Phagocytic activity } \\
\hline All subjects (\%) & - & $86 \cdot 3$ & $10 \cdot 7$ & $87 \cdot 8$ & 4.9 & ND & & $85 \cdot 7$ & 7.4 & $83 \cdot 8$ & $9 \cdot 0$ & ND & \\
\hline Subject with low levels (\%)‡ & - & $80 \cdot 3$ & $12 \cdot 8$ & $88 \cdot 0^{\star}$ & $6 \cdot 6$ & ND & & $79 \cdot 8$ & $6 \cdot 0$ & 77.9 & 8.9 & ND & \\
\hline C-reactive protein $(\mathrm{mg} / \mathrm{l})$ & $0.0-5.0$ & 14.5 & $18 \cdot 7$ & $12 \cdot 1$ & $15 \cdot 5$ & 12.5 & $14 \cdot 1$ & $13 \cdot 2$ & $29 \cdot 0$ & 8.0 & $9 \cdot 1$ & $17 \cdot 7$ & $41 \cdot 2$ \\
\hline TNF- $\alpha(\mathrm{pg} / \mathrm{ml})$ & - & 2.97 & $2 \cdot 30$ & $2 \cdot 27^{\star \star}$ & $2 \cdot 26$ & ND & & 1.78 & 0.87 & 1.73 & & ND & \\
\hline \multicolumn{14}{|l|}{ Other blood biomarkers } \\
\hline AST (IU/I) & $8-38$ & $26 \cdot 0$ & $10 \cdot 1$ & $24 \cdot 1$ & $8 \cdot 1$ & $24 \cdot 0$ & 9.5 & $25 \cdot 7$ & 9.9 & $22 \cdot 8$ & $6 \cdot 3$ & $22 \cdot 8$ & 5.5 \\
\hline ALT (IU/I) & $4-44$ & $25 \cdot 4$ & $18 \cdot 4$ & $23 \cdot 0$ & $14 \cdot 0$ & 23.4 & 8.9 & $20 \cdot 7$ & $12 \cdot 4$ & 18.4 & 5.9 & $19 \cdot 7$ & $7 \cdot 2$ \\
\hline Cholinesterase (IU/I) & $200-400$ & 105 & 42 & $114^{*}$ & 42 & 113 & 46 & 102 & 30 & 105 & 32 & 109 & 34 \\
\hline BUN (mg/l) & $80-210$ & 215 & 73 & 225 & 79 & 233 & 96 & 269 & 145 & 296 & 148 & 308 & 143 \\
\hline Creatinine (mg/l) & $3-11$ & 5 & 2 & 5 & 2 & 5 & 2 & 7 & 4 & 7 & 4 & 8 & 4 \\
\hline White blood cells $(\times 100 / \mu l)$ & $40-80$ & 66.5 & $27 \cdot 1$ & $78 \cdot 6$ & 34.5 & $77 \cdot 3^{*}$ & $25 \cdot 5$ & $58 \cdot 3$ & $20 \cdot 8$ & 63.7 & 9.7 & $68 \cdot 1$ & 13.4 \\
\hline Erythrocytes $(\times 10000 / \mu l)$ & $370-570$ & 359 & 36 & $395^{\star} \dagger$ & 47 & 377 & 40 & 352 & 54 & 330 & 53 & 365 & 47 \\
\hline $\mathrm{Hb}(\mathrm{g} / \mathrm{l})$ & $113-174$ & 111 & 20 & $125^{\star} \dagger$ & 18 & $121^{*}$ & 17 & 113 & 17 & 107 & 16 & 117 & 15 \\
\hline Platelets (\%) & $12-38$ & 28.5 & $9 \cdot 6$ & 26.5 & $10 \cdot 3$ & $27 \cdot 8$ & $10 \cdot 7$ & $25 \cdot 2$ & 7.4 & $26 \cdot 7$ & $7 \cdot 2$ & $26 \cdot 1$ & 8.3 \\
\hline Lymphocytes (\%) & $20-55$ & $25 \cdot 8$ & $9 \cdot 3$ & $23 \cdot 8$ & $7 \cdot 1$ & $25 \cdot 7$ & $13 \cdot 0$ & $25 \cdot 3$ & $8 \cdot 7$ & $25 \cdot 2$ & 8.2 & $26 \cdot 0$ & 9.9 \\
\hline Neutrophils (\%) & $37-73$ & $62 \cdot 8$ & 11.5 & $67 \cdot 3$ & 8.2 & 63.7 & 13.6 & $63 \cdot 6$ & 11.9 & $61 \cdot 8$ & $12 \cdot 8$ & $60 \cdot 8$ & $10 \cdot 4$ \\
\hline Eosinophils (\%) & $0.5-11$ & 3.4 & 1.8 & $2 \cdot 8$ & $2 \cdot 4$ & 3.7 & $2 \cdot 6$ & 4.2 & $3 \cdot 2$ & $5 \cdot 3$ & $7 \cdot 0$ & $5 \cdot 2$ & $4 \cdot 2$ \\
\hline Basophils (\%) & $0-2$ & 0.4 & 0.3 & 0.3 & 0.2 & 0.5 & 0.4 & 0.2 & 0.2 & 0.4 & 0.2 & 0.3 & 0.3 \\
\hline
\end{tabular}

LC1, Lactobacillus johnsonii La1; ND, not determined; AST, aspartate aminotransferase; ALT, alanine aminotransferase, BUN, blood urea nitrogen

Mean value was significantly different from that at 0 weeks: ${ }^{*} P<0.05,{ }^{*}{ }^{*} P<0.01$.

¥ Subjects whose basal phagocytic activity was lower than $90 \%, \operatorname{LC} 1(n 6)$ and control $(n 6)$. 
could play a key role in the regulation of infections by revitalising the immune system and organs. Diarrhoea may cause malnutrition, which can be reversed by probiotics through the regulation of diarrhoea by normalising intestinal microbiota $^{48}$. In the present study, however, incidence of diarrhoea was low from the beginning, and we did not find any changes in its incidence or faecal microbiota by the probiotic feeding, indicating that improvement of nutritional status found in the present study was not likely to have occurred through an anti-diarrhoeal effect. Recently, we found that duodenal administration of the La1 strain stimulates the parasympathetic nervous system in vivo ${ }^{49,50}$. Physiological declines of gastrointestinal functions, including not only of immunological but also neurological and metabolic systems, occur in aged populations ${ }^{51}$. The probiotic strain may act as an anabolic stimulus to the intestines through the auto-nervous system and may revitalise the digestive and absorption systems. We observed in the present study that the inflammatory blood parameter TNF- $\alpha$ decreased in the probiotic-fed subjects. The anti-inflammatory action of the La1 strain is also shown in an in vitro epithelial cell-culture model ${ }^{34}$. The decrease in inflammation and fever associated with the regulation of infections might lower the unexpected expenditure of energy and nutrients of the body. These findings imply that the intestinal stimulation and anti-inflammatory effects of the La1 strain might explain the mechanisms of it on the nutritional status improvement.

Immune reinforcement by probiotics may play a key role in the reduction of infections. In the present study, blood phagocytic activity, a biomarker for natural immunity, increased with probiotic feeding in the elderly subjects who had low initial activity. Ageing influences haematopoietic stem cells and lymphocytes ${ }^{52}$ and we found slight recovery of blood cell numbers in the subjects of the LC1 group. Probiotics, as bacteria, potentially stimulate the host immunity directly ${ }^{22,30}$, after being recognised by the host through antigen-presenting cells such as dendritic cells in the intestinal tract ${ }^{53}$ and at the Payer's patches ${ }^{54}$, or through intestinal epithelial cells covering the huge surface of the intestine ${ }^{33}$. The decrease in infections found in the present study may be totally caused by nutritional status improvement, immune enhancement and anti-inflammation, which were triggered by feeding of the fermented milk containing the La1 probiotic strain.

In healthy children and adults, probiotic feeding generally exerts intestinal microbiota improvement and other effects such as immune reinforcement at the same time, and it is therefore difficult to distinguish the direct effect of the probiotic strain from the indirect effect through growth of residential bacteria influenced by probiotic feeding. Interestingly, the present study provides the evidence that feeding of fermented milk containing a single probiotic strain may improve nutritional status and immunity without any help of proportional changes in the residential bacteria. It is a common finding that the administration of lactobacilli results in an increase in bifidobacteria ${ }^{32,55}$, where a huge variety of bacterial strains are involved in changing intestinal microbial ecology. While we expected to improve intestinal microbiota in the elderly with poor bacterial mass and diversity, especially in total enterally fed subjects ${ }^{7}$, not just a single strain but a probiotic cocktail or combination with prebiotics ${ }^{56}$ could be needed to provide the missing links in the chain of bacterial metabolite-growth elements network. 
In spite of observing no changes in faecal microbiota, the present study showed that probiotic feeding suppressed the appearance of the faecal antibiotic-resistant strain methicillin-resistant Staphylococcus aureus, which may cause opportunistic infections ${ }^{57}$. Probiotic feeding could therefore be beneficial in the elderly not only to reduce the incidence of infections but also to reduce the negative impact of antibiotics used in medical facilities. These effects could be directly provided by probiotic feeding, independently from indirect influence through intestinal microbiota.

In conclusion, feeding of the probiotic L. johnsonii La1 on top of a well-designed nutritional supplement may reduce the risk of infections through improvement of nutritional status and immune function in the elderly, contributing to improvement in their quality of life.

\section{Acknowledgements}

The present study was conducted with a research grant from the Applied Science Board for Lactic Acid Bacteria (Tokyo). We wish to express our appreciation to Mitsubishi Kagaku BCL Inc. (Tokyo) and FALCO Biosystems Ltd (Kyoto) for carrying out the blood and faecal analyses. We also gratefully thank all volunteers who participated in the study.

\section{References}

1. Japanese Cabinet Office (2006) Aging Society White Paper. Tokyo: Cabinet Office.

2. Winker M (1997) Aging: a global issue. J Am Med Assoc 278, 1377-1378.

3. Klima MP, Povysil C \& Teasdale TA (1997) Causes of death in geriatric patients: a cross-cultural study. J Gerontol A Biol Sci Med Sci 52, M247-M253.

4. Miller RA (1996) The aging immune system: primer and prospectus. Science 273, 70.

5. Makinodan T (1995) Patterns of age-related immunologic changes. Nutr Rev 53, S27-S31.

6. Sullivan DH, Sun S \& Walls RC (1999) Protein-energy undernutrition among elderly hospitalized patients. JAMA 21, 2013-2019.

7. Schneider SM, Le Gall P, Girard-Pipau F, Piche T, Pompei A, Nano JL, Hebuterne X \& Rampal P (2000) Total artificial nutrition is associated with major changes in the fecal flora. Eur $J$ Nutr 39, 248-255.

8. Keusch GT (2003) The history of nutrition: malnutrition, infection and immunity. $J$ Nutr 133, 336S-340S.

9. Lesourd B (2004) Nutrition:a major factor influencing immunity in the elderly. $J$ Nutr Health Aging 8, 28-37.

10. Lio D, Scola L, Crivello A, et al. (2003) Inflammation, genetics, and longevity: further studies on the protective effects in men of IL-10 -1082 promoter SNP and its interaction with TNF- $\alpha-308$ promoter SNP. J Med Genet 40, 296-299.

11. Fortes C, Forastiere F, Agabiti N, et al. (1998) The effect of zinc and vitamin A supplementation on immune response in an older population. J Am Geriatr Soc 46, 19-26.

12. Thies F, Miles EA, Nebe-von-Caron G, Powell JR, Hurst TL, Newsholme EA \& Calder PC (2001) Influence of dietary supplementation with long-chain $n-3$ or $n-6$ polyunsaturated fatty acids, decreases natural killer cell activity in healthy subjects aged > 55y. Am J Clin Nutr 73, 539-548.

13. Chandra RK (1992) Effect of vitamin and trace-element supplementation on immune responses infections in elderly subjects. Lancet 340, 1124-1127.
14. Girodon F, Galan P, Monget AL, Boutron-Ruault MC, BrunetLecomte P, Preziosi P, Arnaud J, Manuguerra JC \& Herchberg S (1999) Impact of trace elements and vitamin supplementation on immunity and infections in institutionalized elderly patients: a randomized controlled trial. MIN. VIT. AOX. geriatric network. Arch Intern Med 159, 748-754.

15. Graat JM, Schouten EG \& Kok FJ (2002) Effect of daily vitamin $\mathrm{E}$ and multivitamin-mineral supplementation on acute respiratory tract infections in elderly persons: a randomized controlled trial. JAMA 288, 715-721.

16. Wells CL, Maddaus LA, Jechorek RP \& Simmons RL (1988) Role of intestinal anaerobic bacteria in colonization resistnace. Eur J Clin Microbiol Infect Dis 7, 107-113.

17. Mitsuoka T, Ohno K, Benno Y, Suzuki K \& Nanba K (1976) The fecal flora of man. IV. Communication of the newly developed method with the old conventional method for the analysis of intestinal flora (article in German). Zentralbl Bakteriol Hyg I Abt Orig A 234, 219-233.

18. Hopkins MJ, Sharp R \& Macfarlane GT (2001) Age and disease related changes in intestinal bacterial populations assessed by cell culture, 16S rRNA abundance, and community cellular fatty acid profiles. Gut 28, 198-205.

19. Dineen P (1961) The effect of alterations in intestinal flora on host resistance to systemic bacterial infection. J Infect Dis 109, 280-286.

20. Fuller R (1991) Probiotics in human medicine. Gut 32, 439-442.

21. Food and Agricultural Organization/World Health Organization Joint Working Group (2002) Guidelines for the Evaluation of Probiotics in Food. May 2002. London, Ontario: WHO.

22. Gill HS \& Guarner F (2004) Probiotics and human health: a clinical perspective. Postgrad Med J 80, 516-526.

23. Saavedra JM, Bauman NA, Oung I, Perman JA \& Yolken RH (1994) Feeding of Bificobacterium bificum and Streptococcus thermophilus to infants in hospital for prevention of diarrhoea and shedding of rotavirus. Lancet 344, 1046-1049.

24. Hatakka K, Savilahti E, Ponka A, Meurman JH, Poussa T, Nase L, Saxelin M \& Korpela R (2001) Effect of long term consumption of probiotic milk on infections in children attending day care centres: double blind, randomized trial. $B r$ Med $J$ 322, $1327-1331$.

25. de Vrese M, Winkler P, Rautenberg P, et al. (2005) Effect of Lactobacillus gasseri PA 16/8, Bifidobacterium longum SP 07/3, B. bifidum MF 20/5 on common cold episodes: a double blind, randomized, controlled trial. Clin Nutr 24, 481-491.

26. Turchet P, Laurenzano M, Auboiron S \& Antoine JM (2003) Effect of fermented milk containing the probiotic Lactobacillus casei $\mathrm{DN}-114001$ on winter infections in free-living elderly subjects: a randomized, controlled pilot study. J Nutr Health Aging 7, 75-77.

27. World Health Organization (2000) Nutrition for Health and Development, pp. 9-10. Geneva: WHO.

28. Bernet MF, Brassart D, Neeser JR \& Servin AL (1994) Lactobacillus acidophilus La1 binds to cultured human intestinal cell lines and inhibits cell attachment and cell invasion by enterovirulent bacteria. Gut 35, 483-489.

29. Bernet-Camard MF, Lievin V, Brassart D, Neeser JR, Servin AL \& Hudault S (1997) The human Lactobacillus acidophilus strain La1 secretes a nonbacteriocin antibacterial substance(s) active in vitro and in vivo. Appl Environ Microbiol 63, 2747-2753.

30. Schiffrin EJ, Rochat F, Link-Amster H, Aeschlimann JM \& Donnet-Hughes A (1995) Immunomodulation of human blood cells following the ingestion of lactic acid bacteria. $J$ Dairy Sci 78, 491-497.

31. Link-Amster H, Rochat F, Saudan KY, Mignot O \& Aeschlimann JM (1994) Modulation of a specific humoral immune 
response and changes in intestinal flora mediated through fermented milk intake. FEMS Immunol Med Microbiol 10, 55-64.

32. Yamano $\mathrm{T}$, Iino $\mathrm{H}$, Takada $\mathrm{M}$, Blum $\mathrm{S}$, Rochat $\mathrm{F}$ \& Fukushima $Y$ (2006) Improvement of human intestinal flora by ingestion of a probiotic strain of Lactobacillus johnsonii La1. Br J Nutr $\mathbf{9 5}$, 303-312.

33. Haller D, Bode C, Hammes WP, Pfeifer AM, Schiffrin EJ \& Blum S (2000) Non-pathogenic bacteria elicit a differential cytokine response by intestinal epithelial cell/leukocyte co-cultures. Gut 47, 79-87.

34. Vidal K, Donnet-Hughes A \& Granato D (2002) Lipoteichoic acids from Lactobacillus johnsonii strain La1 and Lactobacillus acidophilus strain La10 antagonize the responsiveness of human intestinal epithelial HT29 cells to lipopolysaccharide and gramnegative bacteria. Infect Immun 70, 2057-2064.

35. Felley CP, Corthesy-Theulaz I, Rivero JL, et al. (2001) Favourable effect of an acidified milk (LC-1) on Helicobacter pylori gastritis in man. Eur J Gastroenterol Hepatol 13, 25-29.

36. Cruchet S, Obregon MC, Salazar G, Diaz E \& Gotteland M (2003) Effect of the ingestion of a dietary product containing Lactobacillus johnsonii La1 on Helicobacter pylori colonization in children. Nutr 19, 716-721.

37. Mitsuoka T, Ohno K, Benno Y, Suzuki K \& Nanba K (1976) The fecal flora of man. Communication of newly developed method with the old conventional method for the analysis of intestinal flora. Zentralbl Bakteriol Hyg I Abt Orig A 234, 219-233.

38. Uchino U, Kanayama A, Hasegawa M, et al. (1995) Effects of azithromycin on fecal flora of healthy adult volunteers (article in Japanese). Jpn J Antibiot 48, 1119-1130.

39. Sullivan A, Edlund C \& Nord CE (2001) Effect of antimicrobial agents on the ecological balance of human microflora. Lancet Infect Dis 1, 101-114.

40. Esparza B, Sanchez M, Barranquero M, Sabiono E \& Merino F (1996) Neutrophil function in elderly persons assessed by flow cytometry. Immunol Invest 25, 185-190.

41. Davis JM, Murphy EA, Brown AS, Carmichael MD, Ghaffar A \& Mayer EP (2004) Effects of moderate exercise and oat $\beta$-glucan on innate immune function and susceptibility to respiratory infection. Am J Physiol Regul Integr Comp Physiol 286, R366-R372.

42. Kiecolt-Glaser JK, McGuire L, Robles TF \& Glaser R (2002) Emotions, morbidity, and mortality: new perspectives from psychoneuroimmunology. Ann Rev Psychol 53, 83-107.

43. Donnet-Hughes A, Rochat F, Serrant P, Aeschlimann JM \& Schiffrin EJ (1999) Immunomodulatory doses of lactic acid bacteria. Modulation of nonspecific mechanisms of defence by lactic acid bacteria: effective dose. J Dairy Sci 82, $863-869$.
44. Bogden DG, Oleske JM, Lavenhar MA, Munves EM, Kemp FW, Bruening KA, Holding KJ, Denny TM, Guariono MA \& Holland BK (1990) Effects of one year of supplementation with zinc and other micronutrients on cellular immunity in the elderly. J Am Coll Nutr 9, 214-225.

45. Bogden JD, Oleske JM, Lavenhar MA, et al. (1988) Zinc and immunocompetence in elderly people: effects of zinc supplementation for 3 months. Am J Clin Nutr 48, 655-663.

46. Yamori Y, Sagara M, Chen JJ, Yamano T \& Fukushima Y (2004) Immunopotentiation of influenza vaccination and nutritional improvement by LC1 fermented milk in the elderly. $J$ Nutr Health Aging 8, 448.

47. Sullivan DH (2000) Undernutrition in older adults. Ann LongTerm Care 8, 41-46.

48. Solis B, Samartin S, Gomez S, Nova E, de la Rosa B \& Marcos A (2002) Probiotics as a help in children suffering from malnutrition and diarrhea. Eur J Clin Nutr 56, Suppl. 3, S57-S59.

49. Tanida M, Yamano T, Maeda K, Okumura N, Fukushima Y \& Nagai K (2005) Effects of intraduodenal injection of Lactobacillus johnsonii La1 on renal sympathetic nerve activity and blood pressure in urethane-anesthetized rats. Neurosci Lett 389, 109-114.

50. Yamano $\mathrm{T}$, Tanida M, Niijima A, Maeda K, Okumura N, Fukushima Y \& Nagai K (2006) Effects of the probiotic strain Lactobacillus johnsonii strain La1 on autonomic nerves and blood glucose in rats. Life Sci 79, 1963-1967.

51. Firth M \& Prather CM (2002) Gastrointestinal motility problems in the elderly patient. Gastroenterology 122, 1688-1700.

52. Linton PJ \& Dorshkind K (2004) Age-related changes in lymphocyte development and function. Nat Immunol 5, 133-139.

53. Rescigno M, Urbano M, Valzasina B, Francolini M, Rotta G, Bonasio R, Granucci F, Kraehenbuhl JP \& Ricciardi-Castagnoli P (2001) Dendritic cells express tight junction proteins and penetrate gut epithelial monolayers to sample bacteria. Nat Immunol 2, 361-367.

54. Takahashi M, Iwata S, Yamazaki N \& Fujiwara H (1991) Phagocytosis of the lactic acid bacteria by $\mathrm{M}$ cells in the rabbit Peyer's patches. $J$ Clin Electron Microscopy 24, 5-6.

55. Spanhaak S, Havenaar R \& Schaafsma G (1998) The effect of consumption of milk fermented by Lactobacillus casei strain Shirota on the intestinal microflora and immune parameters in humans. Eur J Clin Nutr 52, 899-907.

56. Guigoz Y, Rochat R, Perruisseau-Carrier G, Rochat I \& Schiffrin EJ (2002) Effect of oligosaccharide on the faecal flora and non-specific immune system in elderly people. Nutr Res 22, $13-25$.

57. Siu AC (1994) Methicillin-resistant Staphylococcus aureus: do we just have to live with it? Br J Nurs 3, 753-759. 